\title{
Fifty years of the Journal
}

The founding editor of the Journal of the College of General Practitioners was RMS 'Mac' McConaghey, and the first issue of this title, separate from the College's Research Newsletter, appeared in February 1960. In September 1953 Robin Pinsent had launched the Research Newsletter, where the first paragraph read:

\begin{abstract}
'The White Paper on Clinical Research in relation to the National Health Service' is a milestone in the history of man's inquiry into sickness and disease; for the definition of research laid down by the joint committee expressly includes field studies in epidemiology and in social medicine, and observations in general practice. It is clearly implied that research in the field of medicine seen by the general practitioner is potentially as valuable as that carried out in a hospital ward or a university department. This is a challenge to those in general practice, who see the beginnings of disease, to make a fuller contribution to its study by investigating more fully the problems they handle.'
\end{abstract}

This far-sighted statement of the need for a research evidence base for general practice and primary care set the tone for the early observational studies of disease in the community by Fry, Watson, and others, whose landmark papers continue to guide practice and to inform prognosis. With McConaghey still at the helm, the Journal of the Royal College of General Practitioners appeared in 1967 and his 1969 editorial 'Why a College Journal?' still bears re-examination. ${ }^{2}$ As part of a strong editorial board Denis Pereira Gray became deputy editor and took the editorial chair in 1972. His massive contribution to the development of the Journal - including strengthening its original research content, looking critically at postgraduate education and clinical practice and negotiating new publishing arrangements - are summarised in a leader by his successor, Simon Barley, in the January 1981 edition. ${ }^{3}$ Barley passed the baton to Graham Buckley in 1983 and, supported by a stellar editorial board, the JRCGP continued to flourish, becoming the British Journal of General Practice in 1990. Like his predecessors', Buckley's valedictory leader, on editorial freedom, ${ }^{4}$ reflected the considerable challenges as well as the achievements of having stewardship of a journal from which very different things are expected by the varied constituencies that make up general practice.

The prevalence of Scottish journal editors rose further when Alastair Wright took over the editorship in March 1991. The Journal office moved from Edinburgh to the London College and Wright began to get to grips with journal citation rates, impact factors and the impending seachange caused by electronic publishing. The recruitment of Alec Logan as deputy editor meant that for the coming years readers of the BJGP could look forward to the treasure trove of views, reviews, arts and sciences that make up the popular Back Pages section of the Journal.

A new decade brought a new editor and David Jewell took up residence in the garret in Princes Gate and with him brought a mix of rigour, literacy, and attention to detail that ensured continuing high quality publications and a steadily rising impact factor - the bibliometric grail of editors, and of authors and researchers in the university world. The Journal approached paper short: web long publishing with increased energy and, as David pointed out in his robust farewell piece, written with nods to Evelyn Waugh, Schiller and Private Eye, moved ahead of the field in its use of open peer review. ${ }^{5}$

Another decade, another editor, with much to accomplish in the future, and much to live up to from the past. We asked previous editors of the Journal for some pithy words of wisdom and reminiscence, and are pleased to print their contributions below.

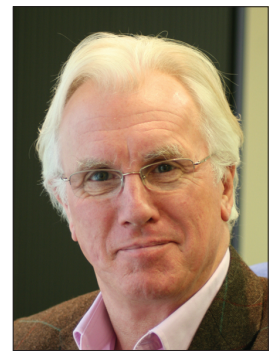

Roger Jones

RMS McConaghey, second Honorary Editor of the Research Newsletter, Between Ourselves, 1954-1957; Honorary Founding Editor of The Journal of the College of General Practitioners, 1958-1966, Honorary Editor Journal of the College of General Practitioners, 1967-1971

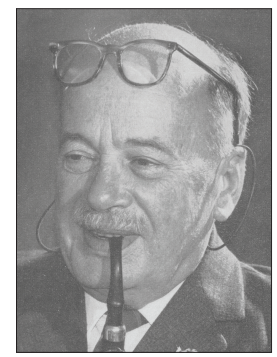

RMS McConaghey, always known as Mac, a GP in Dartmouth, Devon was invited to represent the South Western Region on the Foundation Council of the College. He never sought the editorship, but when Robin Pinsent fell ill he stepped into the breach taking over a cyclostyled newsletter called Between Ourselves, sent out to a closed, limited circulation of research enthusiasts.

$\mathrm{He}$ later wrote $^{6}$ that he was quite untrained and unprepared for this role, which he undertook as a full-time GP without payment and indeed initially paid his own travelling expenses to London. Such was the commitment of the founders.

The Journal office was one room in the 
family home and Mac, well supported by Miss Irene Scawn, Business Manager, edited and published the Journal from there using local printers. He frequently had to add references for articles from his own extensive library. ${ }^{7}$

The initial editorial board, all with MDs, gave strong support. The transformation Mac achieved was the greatest of the early achievements of the College of General Practitioners. Starting in October 1954, he moved swiftly, first removing the limited circulation label and making the strategic breakthrough in January 1958, renaming it the Journal of the College of General Practitioners. Then, in 1960, he published it separately under this title.

It is easy to underestimate the extent of Mac's achievement. In the 1950s, he insisted that this Journal contained peerreviewed research articles from general practice, when many did not then see general practice as a field for research at all. He faced sustained criticism within the College from members who did not understand the strategic stakes and who called for review articles from specialists.

This immense success can be illuminated in two ways. First, by comparison with the many other Englishspeaking colleges of general practice around the world, all of which established journals and none of which initially developed a journal of record. ${ }^{8}$

Secondly, in 1961, the National Library of Medicine in Washington US, independently included this Journal in Index Medicus - international recognition of the existence of a unique body of knowledge. ${ }^{9}$ This was the historic turning point. Two years before there was a professor of general practice anywhere in the world, the small, 9-year-old, highly decentralised, College of General Practitioners, with its scholarly honorary editor in a remote provincial practice, established general practice as a new independent discipline, for the first time in the world.

\section{Denis Pereira Gray,}

Member of Dr McConaghey's editorial board.
Denis Pereira Gray, Honorary Editor, Journal of the Royal College of General Practitioners, 1972-1980, and College Publications, Exeter, 1972-1999

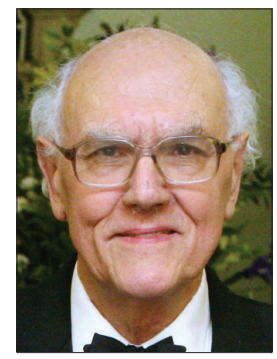

I was appointed in late 1970 to be deputy editor to RMS McConaghey in 1971 and succeeded as editor on 1 January 1972. My wife and I established the Journal office in one room in our home and the entire staff was one secretary. Proofs were checked on Cornish beaches!

The aims were to build up the academic standing of what was then the only peerreviewed general practice journal in the world included in Index Medicus. Scientific rigour was fostered with rigorous peer review and statistical assessors. Challenging editorials were introduced, the news and letter sections expanded, and controversy accepted. ${ }^{3}$ Behavioural medicine was introduced. More articles from overseas and numerous reports from general practice and supplements were published. ${ }^{8,10-11}$

College Officers supported me solidly: understanding the importance of developing a scientific basis for general practice, by spending at times almost $20 \%$ of the College's budget on the Journal, and defending editorial freedom. The subtitle of the British Journal of General Practice was adopted in January 1976 to protect it and was made the title of the Journal by a later editor in 1990 .

In 1976, the editorial board approved a new series of academic publications, the Occasional Papers, for high quality manuscripts too long for a journal article, which were to be sold. These were edited and published from Exeter and greatly extended the academic base of the discipline. By the next year, 1000 were sold and they later broke even. My wife, Jill, who had formerly worked in a London editorial office, was appointed by the
College as assistant editor in 1976, professionalising the office, and much improving the subediting and proofreading. The next year, the College changed its publishing contract for the Journal. Books were published in a white cover series.

During this period, citations to the Journal doubled and its position as the world's highest rated general practice journal of record was maintained. The Journal was increasingly mentioned in the national press and the number of private subscription rose from 379 to just under 1000.

The next Editor, Dr SL Barley, was the first the College appointed with paid consultant sessions, so the Journal's Honorary Editorships ended in December 1980. He chose not to take on the Occasional Papers, as well as the Journal, so the College's Editorships separated and I continued as Honorary Editor and Publisher of the Occasional Papers until 1999, producing 78 in all.

\section{Denis Pereira Gray}

$$
\star * * * *
$$

\section{Simon Barley, Editor, Journal of the Royal College of General Practitioners, 1981-1982}

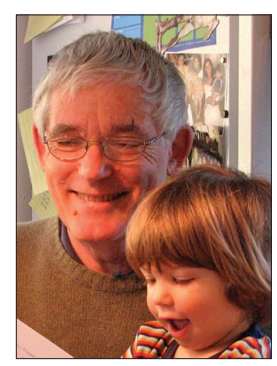

I left the Journal in 1982 and general practice in 1991; dates in the last millenium are becoming Proustianly distant, and an email containing the letters $B J G P$ revived one feeling only, and the one which was dominant throughout my 2 years in the job: anxiety. Enjoyable though some aspects of editing were for me, I believe my appointment was an example of the principle that an excellent deputy is not always the best person to 
be promoted. The smooth machine that came to Sheffield from Exeter was not firing on all cylinders when it moved to Edinburgh, and the driver was burned out from trying to do too many jobs at once.

To be more positive, I can say that my aim was to make the Journal something that the bulk of the members would look forward to reading, and that they would be moved to feel a greater sense of involvement in their College. I therefore included very detailed reports of Council meetings, and with the help of Denis and Colin Waine (chairman at the time) we started to include a larger and easily identifiable section of College News. Whether the quality of the research we printed was good enough to make readers want to apply the lessons to themselves, who knows? General practice probably now contains a smaller proportion of doctors who we would prefer not to look after us, but I can't think I had even a tiny part in that. Over the next 50 years I hope that the Journal will be edited by people who are wise, rather than apparently clever. Appointing a woman would perhaps be a welcome change.

Since I retired and buried my stethoscope in the garden on my 60th birthday, I have had nothing to do with medicine. I have been extremely happy, first in converting a 19th century Yorkshire barn, and then becoming deeply immersed in researching the history of Sheffield saw manufacturing. I have become, as my mother told me when she was dying and could finally confess what it had been like to hear me during the 9 years it took to complete my $\mathrm{PhD}$, a saw bore. I hope that the photograph (I'm on the left, being helped by one of our grandsons to open a recent birthday present) says all the rest.

\section{Simon Barley}

\section{Graham Buckley, Editor, Journal of the Royal College of General Practitioners and British Journal of General Practice, 1983-1991}

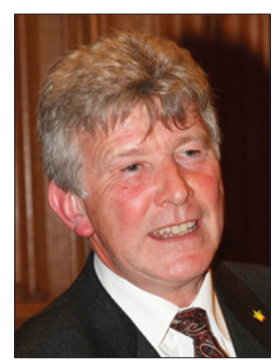

Looking back is seductive but risky. Distance provides perspective but not necessarily objectivity. When asked to reflect on my years as editor of the Journal in the 1980s, I was surprised to realise that the personal and even emotional charge from the period colours my view of the matters of the day that were of importance for the development of the Journal.

Some issues and questions for the Journal have been present from the first publication 50 years ago because they go to the heart of general practice. For a discipline with elastic boundaries, focused on the health of individuals, what are useful, legitimate, and relevant forms of enquiry? For too long this question has been unhelpfully posited as a conflict between quantitative and qualitative research when what is required is high quality research using both paradigms. For a journal of record a second recurring question is the balance to be struck between the publication of original research, analysis of evidence of good practice, and commentary on the interface between medicine and the sociopolitical context of the day.

In the 1980s these overarching issues were experienced in a strained relationship between the College and the Journal. Ironically, my appointment was possibly related to the fact that I was a practitioner in a service practice rather than working in academia. A strong view was expressed through the College Council that the Journal should not focus on the publication of original research as this was seen to be of benefit to the authors rather than the readers. For a time it was uncomfortable to be defending the need for a journal that was seeking to establish a solid research base for our discipline. Quite unrelated events in the College, the resignation of the Chief Examiner and then the Chairman of Council, suddenly changed the political environment. Academic respectability and the independence of the editor became high priorities. This made possible the change of title to the British Journal of General Practice as an unambiguous indication of the purpose, standing, and independence of the Journal.

As a relatively young doctor, my time as editor was exhilarating and demanding. In retrospect, in the 1980s general practice research and the Journal changed from being cottage industries to more professionally organised activities. The College also changed by becoming the direct publisher of the Journal and guaranteeing the independence of the editor.

\section{Graham Buckley}

\section{Alastair F Wright, Editor, British Journal of General Practice, 1991-1999}

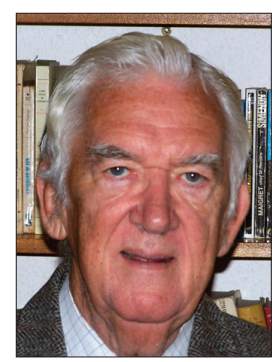

The Edinburgh Journal Office was housed in a fine Georgian building of spacious rooms and high ceilings. It felt more like a traditional library than the hectic practice I had just left. Subediting was done carefully by pencil on paper and our sole computer was reserved for word processing. A highlight of my time in Edinburgh was the visit of $\mathrm{HRH}$ the Prince of Wales during his presidency of the College. He showed a keen interest in the work done in the office and in the importance of the Journal for general practice. 
During my time as editor, the BJGP office moved to much smaller quarters at Princes Gate. The change exposed us to ideas from many different constituencies of the College.

I had come from my practice convinced that maintaining high quality clinical work requires good continuing education. This depends directly on the quality of original research work on which education is based. Experience as an editor confirmed me in this belief and sustained policy decisions I had to make from time to time. The Journal in 1997 had published a readership survey from the Midland Faculty which showed a very high claimed readership among College members, a wish for expansion, and for greater diversity of content. I felt that objective evidence was also needed of its scientific impact and value to researchers. Bibliometric analysis based on journal citation rankings is widely used to compare scientific journals. It is objective, international and widely accepted. Citations count the number of times researchers chose not only to read a journal but to cite an article as important to their own research work. Journals may be compared in terms of 'impact factor' and 'immediacy index'. Among listed journals of general practice or family medicine, the BJGP came first in both these measures. It could therefore be judged objectively as probably the most read and influential journal of general practice in the world.

Computerisation was planned but did not arrive during my editorship. Handcorrected proofs went on paper to the printers and there was no online access to a BJGP archive. Readers showed a lively interest calling for an 'eBJGP' and for more than an electronic version of the paper Journal. It would be premature to envisage the demise of the paper Journal but, whatever form it takes, it will continue to be a vital part of the family silver of the College.

\section{Alastair F Wright}

\section{David Jewell, Editor, British Journal of General Practice, 2000-2009}

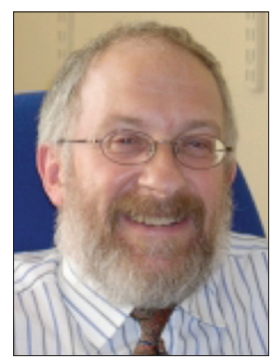

Of all the bits of good fortune that have come my way, one of the best was to have been allowed to edit the BJGP. It meant that for 10 years I was one of those responsible for fostering the quality and reputation of primary care as a serious academic discipline.

The trick as editor was trying to satisfy as many of the different interested parties as possible. Most of the energy went into dealing with the collection of people working in both academic and service environments - who write and review the academic content of the Journal. To anyone complaining that existing in order to service the research community is the Journal's main problem, I would argue, as I always have, that the BJGP is indeed a primary service to the research community; that the College supports it as a gift to that community, in line with its identity as an academic and scientific body as defined in its Charter, and to increase the status of itself and the profession as a whole; and that serious GPs working as clinicians should retain an interest in research informing their own discipline.

Back to the researchers. I never did learn how to reject papers in the most gentle and supportive way, and know that this upset some. To them I send sincere apologies; I know how hard everyone works to write their papers, and it can be very upsetting to be told by some jumped-up editor that it's not good enough. On the other hand authors themselves are notoriously inconsistent. They want a journal with a high impact factor, based on attracting and accepting only the best, but which always accepts their own articles with a minimum of revision required. The interesting aspect of the relationship was the mutual dependency. Authors see the editors as powerful, exercising the arbitrary power of acceptance and rejection; but journals are just as much at the mercy of the authors, knowing that a boycott could leave them with nothing to publish.

As Graham Buckley has written, the difficult relationship was with senior figures and staff at the College. Shortly before I took up the job there had been major disagreements between owners and editors at both JAMA and the New England Journal of Medicine. With such precedents the College was explicit in guaranteeing editorial independence. Most of the time this worked well, to the credit of supportive chairs of UK Council. It cannot come naturally to support a group within your own organisation for them to broadcast disapproval of your policies. However, on two occasions it emerged that some didn't quite understand editorial independence. Future officers may need to be reminded that it means freedom to publish what the parent body finds inconvenient or difficult, not only what it approves of.

After 10 years the editorial pencil has passed into other hands, and the Journal is in rude good health. Changes are being planned and implemented, and quite right too, and with its continued production I have also passed the final test of good stewardship. Thanks be to God!

\section{David Jewell}

\section{REFERENCES}

1. Anonymous. Research Newsletter No. 1. Res Newsl 1953; $\operatorname{Sep}(1): 1$.

2. Anonymous. Why a college Journal? J R Coll Gen Pract 1969; 17(78): 1-2.

3. Barley SL. The nurturing of a medical journal. J R Coll Gen Pract 1981; 31(222): 5.

4. Buckley EG. Editorial freedom. Br J Gen Pract 1991; 41(343): 46-47.

5. Jewell D. So then, farewell: an editor writes. Br J Gen Pract 2009; 59: 952-953.

6. McConaghey RMS. The birth of a medical journal. Postgrad Med J 1960; 36; 306-308.

7. Anonymous. RMS McConaghey. Si monumentum requiris, circumspice. J Roy Coll Gen Pract 1972; 22: 1-4.

8. Fry J, Hunt J, Pinsent RJFH, eds. The first 25 years of the College journal. In: The history of the Royal College of General Practitioners. Lancaster: MTP Press, 1983; 160-177.

9. Anonymous. Mac. J Roy Coll Gen Pract 1975; 25: 627-629.

10. Pereira Gray D. The publishing story. In: Forty years on: the story of the first 40 years of the RCGP. London: Atalink, 1972; 64-78.

11. Anonymous. What kind of Journal? J R Coll Gen Pract 1980; 30(221): 707-709.

DOI: 10.3399/bjgp10X544177 